\title{
Omeprazole $v$ ranitidine for prevention of relapse in reflux oesophagitis. A controlled double blind trial of their efficacy and safety
}

\author{
J Dent, N D Yeomans, M Mackinnon, W Reed, F M Narielvala, D J Hetzel, E Solcia, \\ D J C Shearman
}

Gastroenterology Unit, Royal Adelaide Hospital, Adelaide, Australia

J Dent

D J Hetzel

Department of Medicine, Western Hospital,

Footscray, Australia

N D Yeomans

Gastroenterology Unit, Flinders Medical Centre, Bedford Park, Australia

M Mackinnon

Gastroenterology/Liver

Unit, Sir Charles

Gairdner Hospital

Nedlands, Australia

W Reed

Department of

Gastroenterology,

Repatriation General

Hospital, Daw Park,

Australia

F M Narielvala

Department of

Pathology, University of

Pavia, Pavia, Italy

E Solcia

Department of Medicine, University of Adelaide,

Royal Adelaide Hospital,

Adelaide, Australia

D J C Shearman

Correspondence to:

Professor J Dent,

Gastroenterology Unit, Royal

Adelaide Hospital Adelaide

SA 5000, Australia.

Accepted for publication

20 September 1992

\begin{abstract}
The aim of this study was to compare recurrence rates of reflux oesophagitis (after endoscopic healing with omeprazole) over a 12 month period of randomised, double blind, maintenance treatment with either daily omeprazole ( $20 \mathrm{mg}$ every morning; $\mathrm{n}=53$ ), weekend omeprazole ( $20 \mathrm{mg}$ on three consecutive days a week, $n=55)$ or daily ranitidine $(150$ mg twice daily, $n=51$ ). Patients were assessed for relapse by endoscopy (with gastric biopsy) at six and 12 months, or in the event of symptomatic recurrence, and serum gastrin was monitored. At 12 months, the estimated proportions of patients in remission (actuarial life table method) were $89 \%$ when receiving daily omeprazole compared with $32 \%$ when receiving weekend omeprazole (difference $57 \%, p<0.001,95 \%$ confidence intervals: $42 \%$ to $71 \%$ ) and $25 \%$ when receiving daily ranitidine (difference $64 \%, p<0.001,95 \%$ confidence intervals: $\mathbf{5 0 \%}$ to $\mathbf{7 8} \%$ ). Median gastrin concentrations increased slightly during the healing phase, but remained within the normal range and did not change during maintenance treatment. No significant pathological findings were noted, and no adverse events were attributable to the study treatments. In conclusion, for patients who respond favourably to acute treatment with omeprazole $20 \mathrm{mg}$ every morning, the drug is a safe and highly effective maintenance treatment for preventing relapse of reflux oesophagitis and its associated symptoms over 12 months. By contrast, weekend omeprazole and daily ranitidine were ineffective.

(Gut 1994; 35: 590-598)
\end{abstract}

In a recent study of omeprazole in severe reflux oesophagitis, ${ }^{1}$ we showed that omeprazole $(20$ $\mathrm{mg}$ or $40 \mathrm{mg} /$ day) was associated with over $80 \%$ healing after four weeks, compared with $6 \%$ healing with placebo. As more than $60 \%$ of the patients we studied had grade 3 or 4 oesophagitis, these healing rates were unprecedented.

In the second part of our study, we assessed the pattern and rate of possible recurrence. We found that relapse of the disease occurred quite rapidly when treatment was withdrawn with either $20 \mathrm{mg}$ or $40 \mathrm{mg} /$ day of omeprazole. About
$80 \%$ of the patients had relapsed after six months. Similar relapse rates were seen by Sandmark et $a l,{ }^{2}$ suggesting that reflux oesophagitis is an ongoing disease, which requires continuous treatment to prevent relapses. Omeprazole has a long duration of action, ${ }^{3}$ and its efficacy as a suppressor of acid secretion increases during the first three to five days of repeat treatment because of an increased bioavailability. ${ }^{45}$ In view of its pharmacokinetic profile, we were interested to investigate the safety and efficacy of an intermittent dosing schedule for omeprazole (weekend treatment) and to compare it with a daily dosing schedule for omeprazole or ranitidine as maintenance treatment for erosive or ulcerative reflux oesophagitis.

After an initial healing phase with omeprazole $20 \mathrm{mg}$ daily, patients were randomly allocated to receive one of these three treatment schedules for up to 12 months. They were observed for symptomatic or endoscopic recurrence. In addition to routine safety assessments, gastric biopsy specimens and serial measurements of serum gastrin were undertaken as a surveillance for possible changes in the gastric mucosa, which may result from longterm acid suppression.

\section{Methods}

STUDY DESIGN

Patients were recruited from four Australian centres: Flinders Medical Centre, Bedford Park; Sir Charles Gairdner Hospital, Perth; The Royal Adelaide Hospital and the Repatriation General Hospital, Adelaide. Gastric biopsy specimens were evaluated at two other centres, the Western Hospital in Melbourne and the University of Pavia in Italy. The trial consisted of two phases: (a) an open healing phase using omeprazole 20 mg every morning for four or eight weeks and (b) a randomised double blind maintenance phase comparing three different treatment regimens for up to 12 months: omeprazole $20 \mathrm{mg}$ every morning or omeprazole weekend $(20 \mathrm{mg}$ in the morning on Fridays, Saturdays, and Sundays) or ranitidine $150 \mathrm{mg}$ twice daily.

The study was performed in outpatients aged 
between 18 and 86 years who had erosive reflux oesophagitis of at least grade 2 severity (as defined under 'Endoscopic assessments and definition of oesophagitis'), shown endoscopically within the previous seven days. Patients with benign oesophageal stricture were also entered provided their stricture was dilated before entry. The presence and position of the stricture were recorded and the endoscopic classification of oesophagitis was made before dilatation. Patients with Barrett's oesophagus were eligible for study provided they had concurrent oesophagitis - that is macroscopic erosions or ulceration.

The following exclusion criteria applied: pregnancy or lactation, inadequate contraception, treatment with prokinetic agents or anti-secretory therapy; concurrent peptic ulcer or complications of ulcer disease; gastrointestinal malignancy; oesophagitis resulting from systemic disease, infection, intubation or other mechanical trauma, burns, irradiation or physical deformity; history of oesophagogastric surgery other than simple closure of a perforation or failed anti-reflux surgery without myotomy, vagotomy or a drainage procedure; ongoing upper gastrointestinal haemorrhage (bleeding associated with peptic mucosal damage had to be controlled adequately before entry); concurrent or past disease, for example, severe cardiac, hepatic or renal disease; clinically significant unexpected abnormalities in the assessments before entry or laboratory screen variables; any condition known to be associated with poor patient compliance; treatment with any other investigational drug during the four weeks before or after the initial endoscopy.

In accordance with the Declaration of Helsinki and Tokyo, all patients were informed about the study objectives and procedures and were required to give written informed consent before entering the study. The protocol was reviewed and approved by the ethics review committee at each centre before the study started.

\section{CLINICAL AND LABORATORY ASSESSMENTS}

Assessments made throughout the healing and maintenance phases of the study are summarised in the schedule (Fig 1). Before entry, each patient

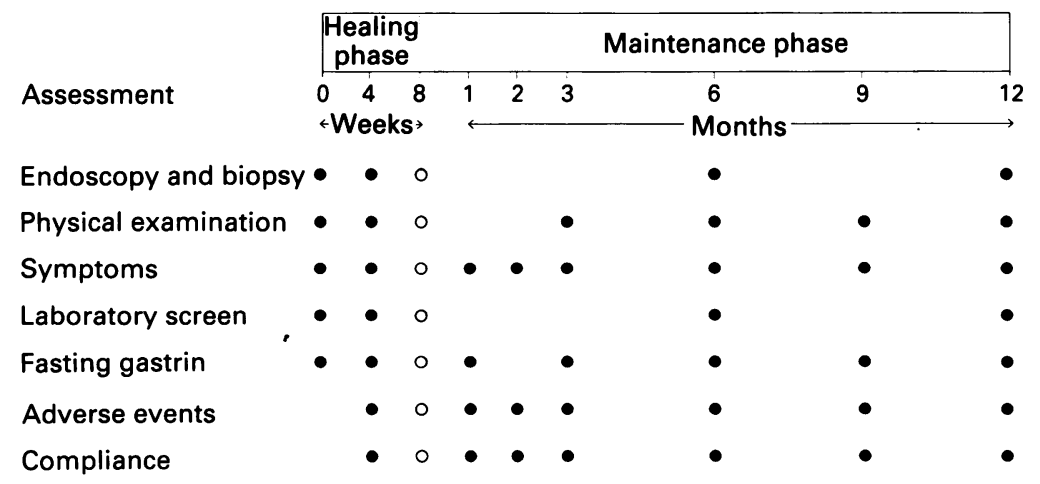

$0=$ only in patients unhealed at 4 weeks had a physical examination and a complete medical and gastrointestinal history was taken. Alcohol and tobacco consumption were recorded and patients were asked about their oesophageal symptoms over the preceding seven days. At each clinic visit, symptoms of heartburn, regurgitation, dysphagia, and nausea were graded as none, mild, moderate or severe and haematemesis, melaena or vomiting were recorded as present or absent. Gastric biopsy specimens were taken during endoscopy at entry and again when patients were healed (at four or eight weeks). A fasting laboratory screen (including gastrin) was also carried out at these time points and included routine haematology, biochemistry (with additional measurements of vitamin B-12 and folic acid) and urine analysis for albumin and sugar.

Patients who remained unhealed after initial treatment with omeprazole or who still had moderate to severe symptoms after eight weeks of omeprazole, left the study and were treated in accordance with current practice.

Patients who were healed by omeprazole and who were asymptomatic or had only mild symptoms were invited to participate in the maintenance part of the study and those who consented were randomised (using a computer randomisation) to receive one of the three maintenance treatment regimens on a double blind basis for one year. They returned to the clinic for review at monthly intervals for the first three months and then at three month intervals for the remainder of the year. During these visits, symptoms, adverse events, and compliance were assessed and laboratory measurements were made according to the schedule (Fig 1). A physical examination was conducted every three months and patients had further endoscopic assessment (and gastric biopsy) at the scheduled times of six and 12 months, or if they reported a recurrence of symptoms that were moderate or severe for three days out of any seven.

\section{Endoscopic assessments and definition of oesophagitis}

The severity and extent of erosive (and ulcerative) lesions of the oesophagus were scored as: grade 0 - normal mucosa, no abnormalities noted; grade 1 - no macroscopic erosions visible, erythema, hyperaemia or friability of the oesophageal mucosa, or both; grade 2 - superficial erosions/ulceration affecting less than $10 \%$ of the mucosal surface of the last $5 \mathrm{~cm}$ of oesophageal squamous mucosa; grade 3 - superficial erosions/ ulceration affecting $10-50 \%$ of the mucosal surface of the last $5 \mathrm{~cm}$ of oesophageal squamous mucosa; grade 4 - deep ulceration anywhere in the oesophagus or confluent erosion/ulceration of more than $50 \%$ of the mucosal surface of the last $5 \mathrm{~cm}$ of oesophageal squamous mucosa. If possible, all endoscopic examinations in any single patient were performed by the same endoscopist, to maintain a consistency of assessment. All endoscopists, however, were familiar with the grading definitions, having used them in a previous study.

At endoscopy after four weeks (and eight weeks, if required) oesophagitis was re-evaluated and patients were defined as healed if grade 0 or 
grade 1 had been achieved - that is, resolution of all macroscopic erosions or ulcers, or both. Only those patients who were healed, and had either no symptoms or mild residual symptoms, were eligible for entry into the maintenance phase of the study. If any patient presented with endoscopically verified oesophagitis of at least grade 2 during the maintenance phase, this was defined as a 'relapse' and the study was terminated for that patient.

\section{Gastrin measurements}

Fasting serum gastrin was measured (always on Fridays before morning dosing) by duplicate batch analysis using a Becton-Dickinson kit with a high affinity antibody (G17 sensitivity $12 \mathrm{pg} /$ $\mathrm{ml}$ ) and minimal cross reactivity (CCK-pancreozymin $1.9 \%$ of G17). The sensitivity of the assay was $15-1000 \mathrm{pg} / \mathrm{ml}$.

\section{Histopathology}

Oesophageal biopsy specimens were taken only to preclude malignancy as and when dictated by the endoscopist's clinical judgment.

In all patients, gastric biopsy specimens (2-4 samples) were taken from the gastric body (oxyntic) mucosa, approximately $10 \mathrm{~cm}$ below the cardia along the greater curvature. All specimens were fixed immediately in formalin and then embedded in paraffin wax. The best two specimens were selected on the basis of orientation and mucosal area and slides, each containing 2-4 sections, were stained using the Grimelius method $^{6}$ for quantitative and qualitative evaluation of their endocrine cell populations. Haematoxylin and eosin staining was used for general pathological examination.

Routine pathology screening and a screening assessment for detecting pathological findings in the endocrine cell population were carried out at Western Hospital, as specimens were received. At the end of the study all slides were coded and randomised so that 'blinded' assessments could be made. A quantitative assessment of the number of Grimelius positive (argyrophil) endocrine cells was also performed. Starting with a randomly selected well orientated region of the specimen, and using an eyepiece graticule that swept a mucosal width of $100 \mu \mathrm{m}$, all Grimelius positive cells in the mucosa in a zone with length $0.5 \mathrm{~mm}$ were counted. The area of sectioned mucosa thus scanned was calculated using depth measurements made with the eyepiece graticule. This was repeated with a section from the second specimen, so that the total mucosal length assessed was $1 \mathrm{~mm}$ (material was sometimes insufficient, in which case a shorter length was assessed). The number of endocrine cells was expressed per $\mathrm{mm}^{2}$ of mucosal area.

An independent assessment of the coded slides was made at the University of Pavia. The presence and grading of gastritis was assessed using the definitions recommended at the World Congress of Gastroenterology working party on Gastritis, Sydney $1990,{ }^{7}$ with the exception of Helicobacter pylori grading, which was not performed. The distribution of inflammatory cells (superficial, neck level or interstitial) was also recorded. This was followed by a qualitative assessment of the number and distribution of endocrine cells, according to previously reported criteria ${ }^{8}$ that is, normal, simple, linear or micronodular hyperplasia, classified as $0,1,2$ or 3 respectively. If more than one classification applied to any one biopsy specimen, only the highest grade was used in the analysis.

\section{ADVERSE EVENTS}

Patients were questioned in a standardised manner at each visit about the occurrence of any unusual or adverse symptoms other than those associated with the primary diagnosis. Patients were withdrawn from the study if any unacceptable adverse event occurred.

\section{DATA ANAL YSIS}

The sample size calculation, made before the study, was based on the assumption that the two extreme treatments - that is, best and worst, would have true relapse probabilities of $20 \%$ and $50 \%$ respectively. After adjustment (which allowed for $20 \%$ drop outs or non-evaluable patients), 50 patients were required in each maintenance group to give an $80 \%$ test power using a two sided test at the $5 \%$ significance value.

All analyses were made using an intention to treat' approach - that is, data from all patients recruited to each part of the study were used in the analyses. Survival - that is, remission curves - were estimated according to the actuarial life table method' using the SAS procedure 'Lifetest'. The endpoint used in the analysis was withdrawal from treatment because of symptomatic or asymptomatic recurrence of endoscopically verified oesophagitis of at least grade 2 . If data were not available up until the point of relapse, they were included up to the time point at which clinical state was last known. Data from such patients were said to be 'censored'. The influence of possible prognostic factors on time in remission was assessed using the Cox regression analysis.

Laboratory variables were analysed, where possible, in terms of mean change from before entry to last visit in the maintenance phase, and $\mathbf{9 5 \%}$ confidence intervals for the mean change were calculated. Differences in mean changes between treatment groups were analysed by a one way analysis of variance. For variables with a highly skewed distribution, a sign test was used to compare the number of patients with increased $v$ decreased values. The pattern of changes was compared between treatments using a $\chi^{2}$ test.

For quantitative assessment of histological changes (gastritis and argyrophil cells) mean changes and $95 \%$ confidence intervals of the changes were calculated before entry $v$ end healing and end healing to end maintenance that is, last biopsy specimen taken), for patients who had paired biopsy data. For qualitative assessment of histological changes, numbers of patients with increased $v$ decreased scores were compared within each treatment group using the sign test and between treatment comparisons of changes were made using the $\chi^{2}$ test. 
TABLE I Demographic characteristics and history of reflux disease

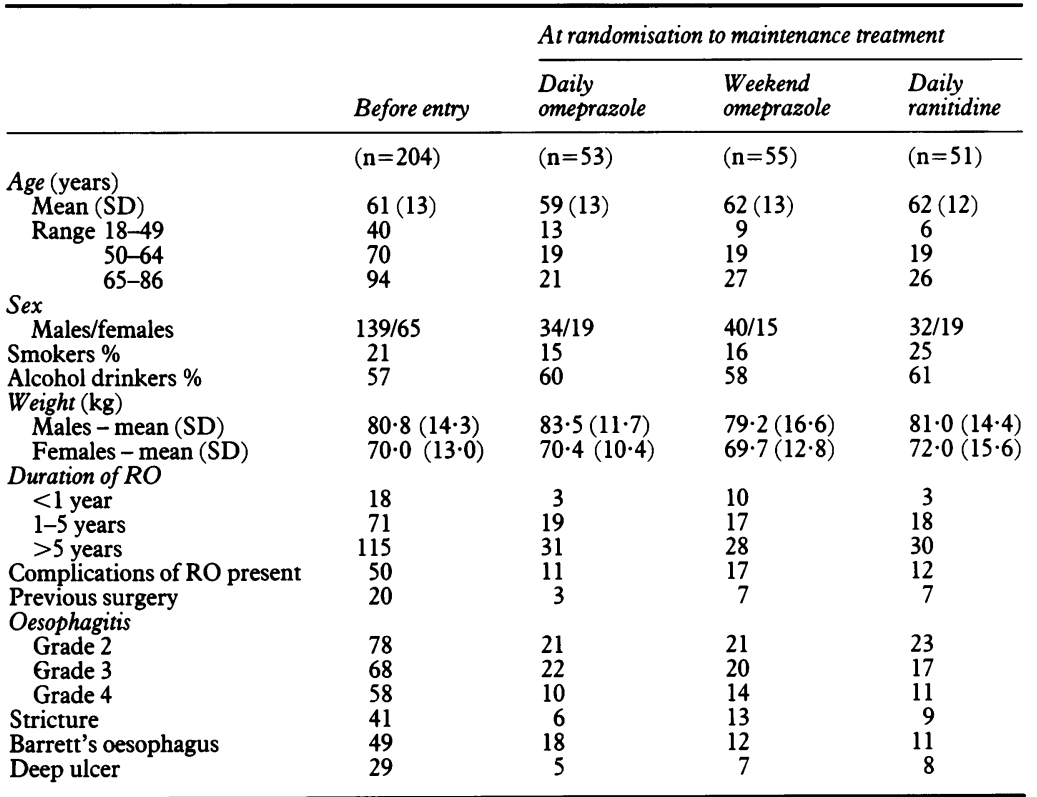

$\mathrm{RO}=$ reflux oesophagitis

\section{Results}

\section{CLINICAL EFFICACY}

Two hundred and four outpatients (139 males and 65 females) were entered into the study between August 1987 and August 1988; 56 were from centre 1,50 from centre 2, 59 from centre 3 , and 39 from centre 4 . Table I gives the demographic details for these patients and their history and the state of oesophagitis at the time of entry. After four weeks of daily omeprazole treatment, $124(61 \%)$ of the patients were healed and after eight weeks' treatment, 165 (81\%). Seven patients were withdrawn from the healing phase because of adverse events (see Safety). Healing was inversely related to disease severity, with $91 \%$ of grade 2 patients and $87 \%$ of grade 3 patients healing, compared with $60 \%$ of grade 4 patients. Hence, there were proportionately fewer patients with grade 4 disease in the maintenance phase than in the healing phase. Of the 165 healed patients, six did not enter the maintenance phase, four because of persistent symptoms, one because of late return for follow up,

\section{patients remaining in omeprazole $20 \mathrm{mg}$ ever

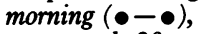 omeprazole $20 \mathrm{mg}$ at weekends $(\bullet--\bullet)$ or ranitidine $150 \mathrm{mg}$ twice daily $(\Delta-\mathbf{\Delta})$, over a period of 12 months.}

Figure 2: Percentage

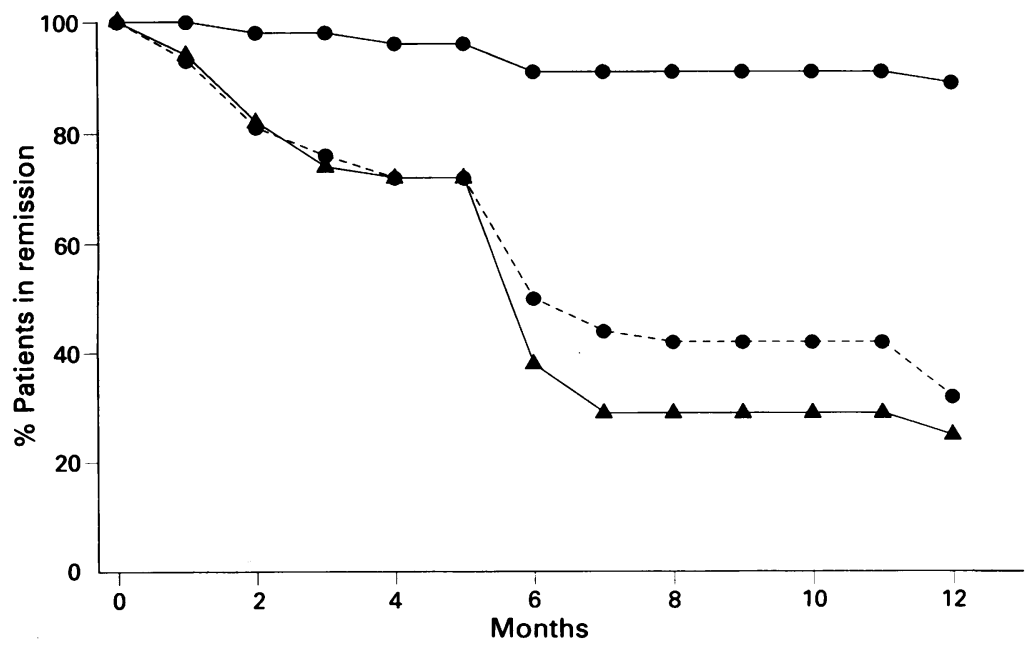

and one who did not wish to participate in the maintenance phase. Hence 159 patients were randomised to the maintenance treatments. Table I summarises the demographic details and disease states for the three maintenance treatment groups. The three groups were reasonably comparable with respect to demographic characteristics, although reflux disease was slightly more severe and had more complications in the weekend omeprazole group.

More than half of the patients had had symptoms of reflux disease for over five years; 40 of the patients had suffered previous complications of the disease (mainly stricture), and 27 patients had had dilatation for the stricture before entry. Seventeen patients had had antireflux surgery (generally fundoplication) and at least half of the patients in each group had been taking other drugs for reflux disease during the month before the study. Previous drugs taken for reflux oesophagitis by patients in the daily omeprazole, weekend omeprazole, and daily ranitidine groups respectively were: $\mathrm{H}_{2} \mathrm{RA}$ $57 \%$, 67\%, $58 \%$; antacids - 36\%, 29\%, 35\%; alginates $-7 \%, 4 \%$, and $7 \%$. Twenty six patients overall took more than one type of drug.

\section{Patients in remission}

According to the calculated survival curves (Fig 2 ), the proportions of patients in remission at the end of 12 months were $89 \%$ (95\% CI, $80 \%$ to $98 \%)$ in the daily omeprazole group, $32 \%(95 \%$ CI, $19 \%$ to $46 \%$ ) in the weekend omeprazole group, and $25 \%(95 \% \mathrm{CI}, 13 \%$ to $38 \%)$ in the ranitidine group. In 20 patients, follow up to the point of relapse was not possible and their data were censored. Reasons for censoring were: no visit performed(A), lost to follow up or refusal of endoscopy (B), withdrawal because of an adverse event (C) or non-compliance with the study protocol (D). Table II gives the numbers of patients who relapsed, did not relapse or were censored (for reasons A, B, C or D).

When a log rank test was performed on these data, a significantly greater proportion of patients treated with daily omeprazole remained in remission at 12 months than those treated with either weekend omeprazole (difference $57 \%$, $95 \%$ CI $42 \%$ to $71 \%, \mathrm{p}<0.001)$ or daily ranitidine (difference $64 \%, 95 \%$ CI $50 \%$ to $78 \%$, $\mathrm{p}<0.001)$. No significant difference was detected between weekend omeprazole and daily ranitidine treatments (difference $7 \%, 95 \% \mathrm{CI}$ $11 \%$ to $25 \%, \mathrm{p}>0 \cdot 20$ ). The possible prognostic influence of treatment, age, sex, oesophagitis grade before entry, and smoking habit on time in remission were tested in a preliminary Cox regression analysis. Age and sex were excluded from the final model as they were non-significant. In the final analysis, there was a significant overall influence of treatment $(p<0.001)$ and oesophagitis grade before entry $(p<0.001)$ on time in remission. The influence of smoking was non-significant. Remission curves show that the relapse rate was higher in patients with more severe oesophagitis treated with ranitidine or weekend omeprazole, while disease severity had little influence on the outcome in patients treated with daily omeprazole. Five patients who 
TABLE II Numbers of patients on each maintenance treatment who relapsed, did not relapse or whose data were censored in the survival analysis

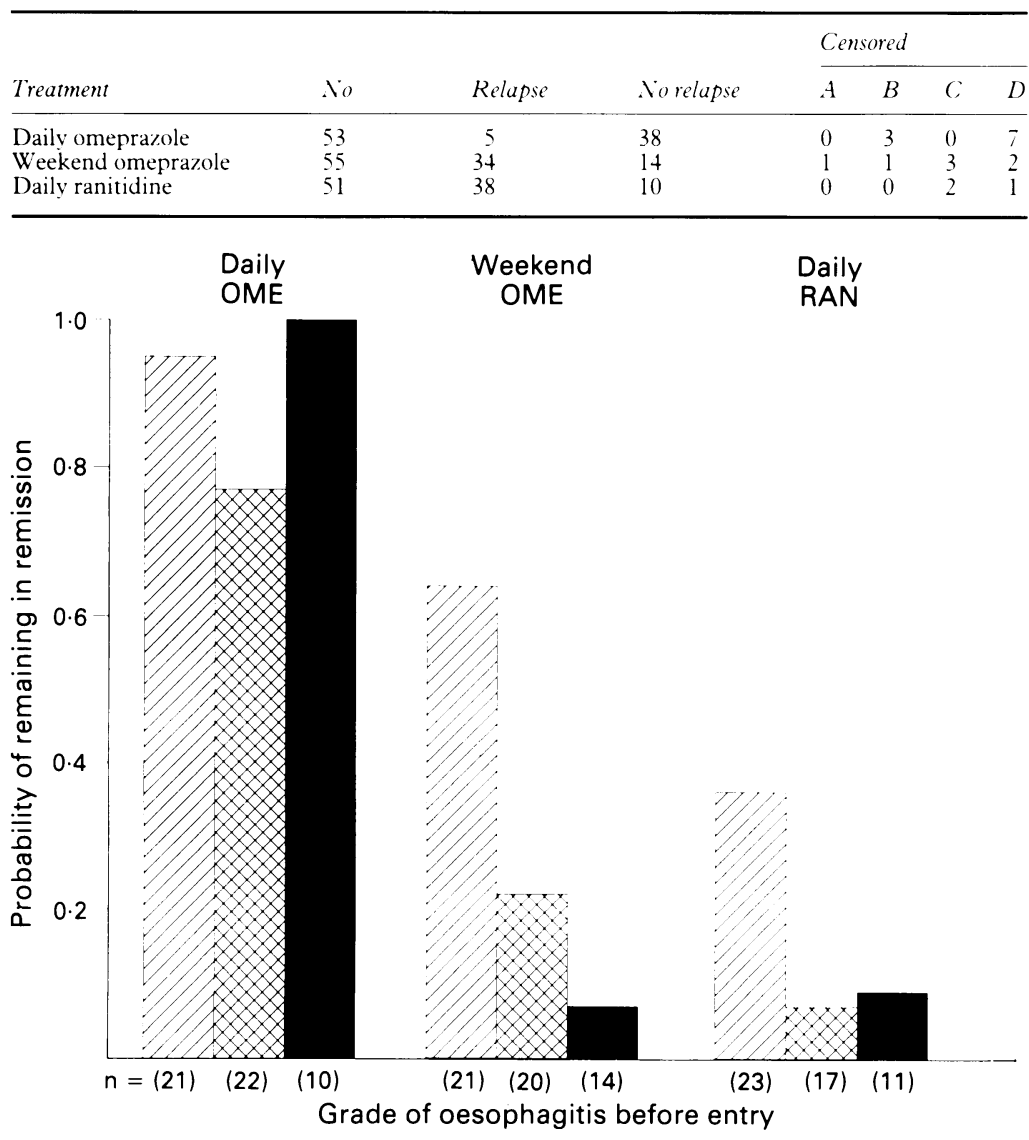

Figure 3: Probability of remaining in remission for each treatment schedule, according to pretreatment grade of oesophagitis where $\boldsymbol{Z}=$ grade $2, \quad=$ grade $3, \mathbf{\square}=$ grade 4 . $O M E=$ omeprazole, $R A N=$ ranitidine.

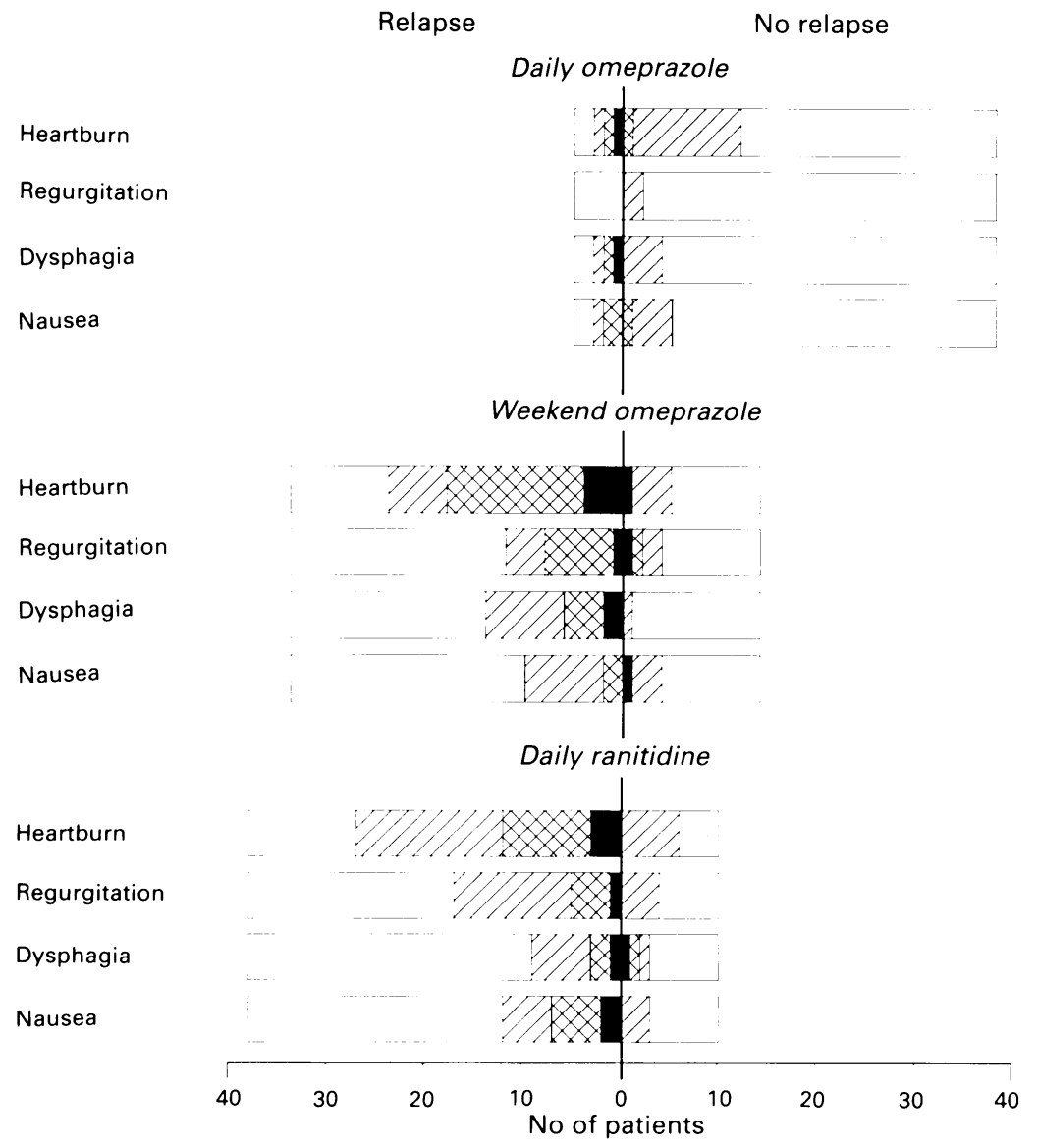

Figure 4: Symptoms (recorded as $\square=$ none, $\boldsymbol{W}=$ mild, $=$ moderate, $\mathbf{\square}=$ severe) reported at time of relapse of oesophagitis (Relapse) or at the end of the study period (No relapse). received daily omeprazole relapsed, of whom four had pre-entry grade 3 and one had pre-entry grade 2 oesophagitis. Careful examination of the data collected for these patients did not point to any obvious factors that might have contributed to their relapse, such as poor compliance, although one of the grade 3 patients also had Barrett's oesophagus and had had two hiatal hernia repairs. Hence, patients receiving daily omeprazole had a higher probability of remaining in remission for 12 months regardless of the severity of their oesophagitis grade before entry (Fig 3).

In patients with symptomatic relapse, heartburn was the predominant symptom. Thirty one patients suffered an asymptomatic relapse, however (one while taking daily omeprazole, 12 while taking weekend omeprazole, and 18 while taking daily ranitidine) and their recurrence was discovered either at routine endoscopy $(n=29)$ or unscheduled extra endoscopy (to investigate weight loss in one patient and to perform dilatation in another). It is important to note, however, that 'symptomatic relapse' was strictly defined in this study and required the presence of moderate or severe reflux symptoms for at least three consecutive days. Half of the patients with 'asymptomatic relapse' had symptoms at relapse, although these were not sufficiently frequent or severe to be classified as 'symptomatic relapse'.

Figure 4 summarises the proportions of patients experiencing symptoms of heartburn, regurgitation, dysphagia or nausea (graded as none, mild, moderate or severe) during relapse or without relapse. These results show that most patients receiving daily omeprazole were symptom free and very few relapsed, while more than half of the patients receiving either weekend omeprazole or daily ranitidine experienced symptoms in association with their high relapse rate. Oesophageal stricture recurred in seven patients taking weekend omeprazole and four patients taking ranitidine and dilatation was required. One patient in the daily omeprazole group had recurrent stricture but was not taking any drugs at the time and was therefore censored from the analysis after month 1 .

\section{SAFETY}

Safety was assessed in all patients who received at least one dose of study drug. Hence 204 patients were assessed for safety in the healing phase, and 158 patients in the maintenance phase (one patient was withdrawn at the beginning of the maintenance phase, before any treatment, because of the persistence of moderate symptoms despite being healed).

Physical examination

There were no significant changes in weight, blood pressure or pulse rate during treatment.

\section{Adverse events}

Twelve patients reported adverse events that resulted in their withdrawal from the study. In four patients these were considered to be serious. Two patients were withdrawn during the healing 
Figure 5: Median serum gastrin concentrations (pg/ml) with 25th and 75 th percentiles (box extremes) 10 th and 90 th percentiles (whisker extremes), five highest and five lowest values (o), as measured before entry, at healing, and at the last visit. $O M E=$ omeprazole, $R A N=$ ranitidine

Figure 6: Median number of argyrophil cells $/ \mathrm{mm}^{2}$ with 25th and 75th percentiles (box extremes), 10th and 90 th percentiles (whisker extremes), five highest and five lowest counts $(o)$, as measured before entry, at healing, and at the last visit. Abbreviations as in Fig 5.

\section{Daily OME} $\mathbf{n}=\mathbf{3 7}$ entry Healing visit

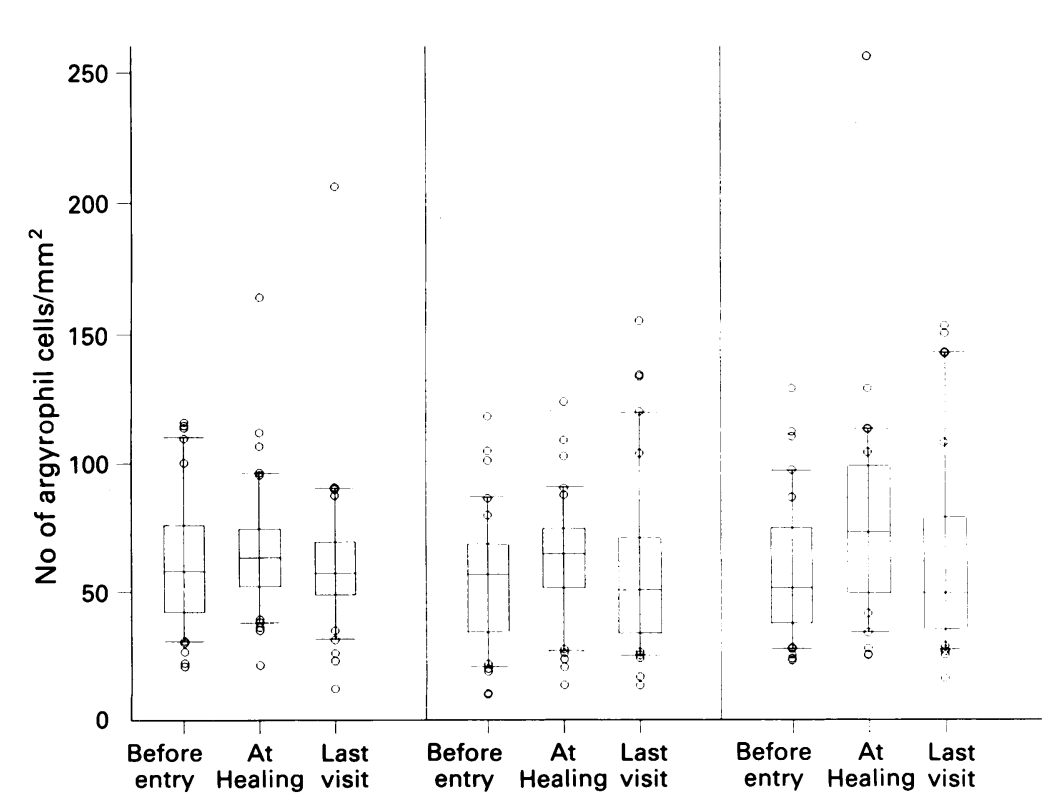

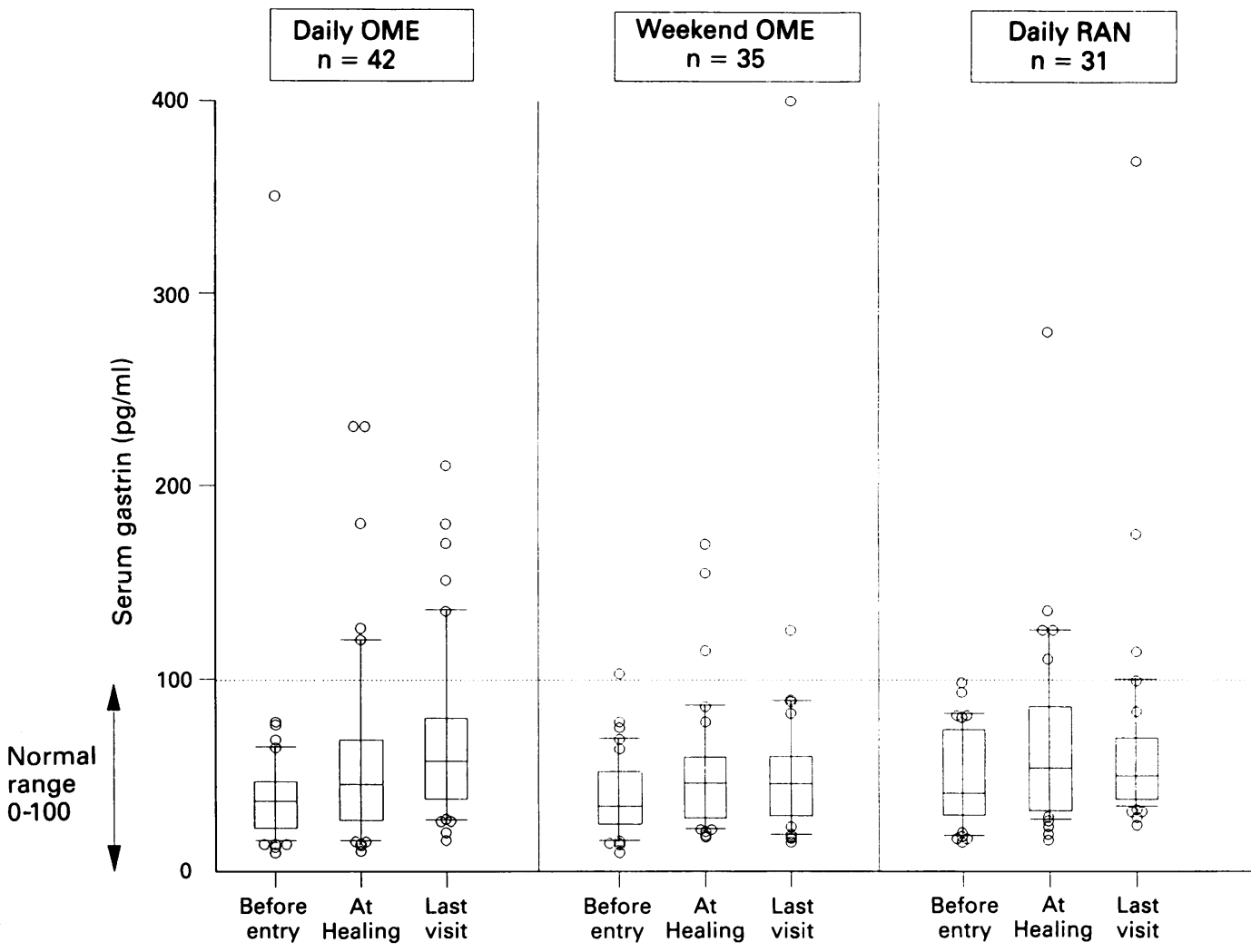

phase, one with newly diagnosed prostatic carcinoma and one because of a cerebral vascular lesion and two patients were withdrawn during maintenance treatment (with weekend omeprazole), one with dysphagia and oesophageal stricture and one with pulmonary embolism. None of the serious adverse events was considered to be attributable to study treatment. A further eight patients were withdrawn from the study because of non-serious adverse events, five from the healing phase during daily omeprazole (dizziness, headache, and abdominal pain; oesophageal ulceration; epigastric pain; nausea and vomiting; dizziness), and three from the main-

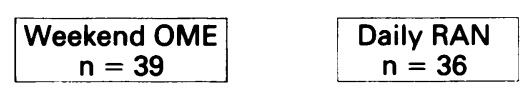

tenance phase (bronchitis while taking weekend omeprazole; epigastric pain; erosive gastritis while taking ranitidine), although none was considered to be attributable to study treatment.

\section{Laboratory examinations}

Haematology and biochemistry - One patient had a history of chronic lymphoid leukaemia, which was considered to be sufficiently stable to permit enrollment to the study. In this patient, the white blood cell count was grossly raised at entry and remained so throughout the 12 month period. A further patient had an unexpected grossly raised alkaline phosphatase activity before entry. Investigation of this showed metastatic adenocarcinoma and the patient was withdrawn. No other clinically significant changes in laboratory variables were seen.

Gastrin-The distribution of gastrin concentrations at entry was highly skewed and so median values have been used to express the results. The median serum concentration for all patients before entry was $37 \mathrm{pg} / \mathrm{ml}$ (normal range $0-100 \mathrm{pg} / \mathrm{ml}$ ) and this increased significantly $(\mathrm{p}<0.001)$ to $47 \mathrm{pg} / \mathrm{ml}$ after four weeks of daily omeprazole treatment. Figure 5 shows the median gastrin values for each treatment group with 10th, 25th, 75th, and 90th percentiles, and extreme outliers (five lowest and highest values). Values obtained 'at healing' reflect the use of omeprazole for four to eight weeks in all three treatment groups - that is, before maintenance. The last gastrin value obtained for each patient during the maintenance phase was used for 'last visit'. Median gastrin concentrations $(\mathrm{pg} / \mathrm{ml})$ at healing and last visit were 46 and 58 for daily omeprazole, 46 and 46 for weekend omeprazole, and 54 and 50 for daily ranitidine. There were no significant changes in gastrin concentrations 
TABLE III Proportion of patients with each degree of hyperplasia at healing $(H)$ and end of maintenance treatment $(M T)$

\begin{tabular}{|c|c|c|c|c|c|c|}
\hline \multirow[t]{2}{*}{ Degree of hyperplasia } & \multicolumn{2}{|c|}{$\begin{array}{l}\text { Daily } \\
\text { omeprazole } \\
(n=39)\end{array}$} & \multicolumn{2}{|c|}{$\begin{array}{l}\text { Weekend } \\
\text { omeprazole } \\
(n=40)\end{array}$} & \multicolumn{2}{|c|}{$\begin{array}{l}\text { Daily } \\
\text { ranitidine } \\
(n=40)\end{array}$} \\
\hline & $\mathrm{H}$ & MT & $\mathrm{H}$ & MT & $\mathbf{H}$ & MT \\
\hline Normal & 34 & 31 & 33 & 35 & 33 & 37 \\
\hline Simple & 4 & 5 & 6 & $\cdot 3$ & 6 & 1 \\
\hline Linear & 1 & 1 & 0 & 1 & 0 & 1 \\
\hline Micronodular & 0 & 2 & 1 & 1 & 1 & 1 \\
\hline Total & & 39 & \multirow{2}{*}{\multicolumn{2}{|c|}{$\begin{array}{l}40 \\
p=0 \cdot 274\end{array}$}} & \multirow{2}{*}{\multicolumn{2}{|c|}{$\begin{array}{l}40 \\
p=0 \cdot 145^{40}\end{array}$}} \\
\hline $\begin{array}{l}\text { Significance of within treatment changes } \\
\text { (sign test) }\end{array}$ & \multirow{2}{*}{\multicolumn{2}{|c|}{$\mathrm{p}=0.291$}} & & & & \\
\hline $\begin{array}{l}\text { Significance of changes between treatment groups } \\
\left(\chi^{2} \text { test }\right)\end{array}$ & & & \multicolumn{2}{|c|}{$\mathrm{p}>0.20$} & & \\
\hline
\end{tabular}

from the start of maintenance to six months or from six months to 12 months in any of the treatment groups.

\section{Histopathology}

Quantitative assessment of argyrophil cells-Figure 6 shows the median numbers of argyrophil cells/ $\mathrm{mm}^{2}$ present in biopsy specimens taken before entry, end of healing phase, and end of maintenance phase (with 10th, 25th, 75th, and 90th percentiles and five lowest and highest values). Mean changes from before entry to healing and from healing to end of maintenance phase were examined statistically for paired data. The last biopsy specimen taken from a patient during maintenance treatment was used for these comparisons. The observed mean number of cells increased slightly from before entry to healing, but the change was not statistically significant. A slight, but statistically insignificant reduction in the mean number of cells was seen for all three treatment groups from healing to end of the maintenance phase.

Qualitative assessment of argyrophil cells-There was a slight increase in the number of patients with hyperplasia from 13 before entry to 24 at healing, although a sign test of the number of increased $v$ decreased scores was not significant $(p=0.09)$. Table III summarises the proportions of patients receiving each treatment with each degree of hyperplasia at healing compared with the end of maintenance treatment. There were no significant changes in the degree of hyperplasia seen from healing to end of maintenance, either within treatment groups or between treatment groups. A few patients exhibited linear or micronodular hyperplasia (focal hyperplasia): $3 \%$ at the beginning of maintenance and $6 \%$ at the end. At the end of maintenance, they were distributed similarly in the three treatment groups (three, two, and two patients respectively receiving daily omeprazole, weekend omeprazole, and ranitidine), and usually were associated with areas of atrophy of the corpus mucosa. No dysplastic or neoplastic lesions of the argyrophilic cell population were detected in the gastric oxyntic mucosa of any patient during the study. The incidence of gastritis before entry was $52 \%$ and this increased slightly to $63 \%$ by the end of the healing phase $(p=0.001$, sign test $)$. This change was entirely due to patients aged 50 years or more and was associated with an increasing trend of gastritis activity $(\mathrm{p}=0.004)$ and intramucosal depth of inflammation $(p=0.022)$. During maintenance treatment, however, mild gastritis improved and the proportion of patients with normal corpus mucosa increased from $36 \%$ at the start of maintenance treatment to $48 \%$ at the end. Sixteen patients had moderate gastritis at the start of the maintenance phase. Of these, nine progressed to a more severe grade at the end (subatrophic or atrophic changes) while two improved. There was also a slight increase in the proportion of biopsy specimens with inflammatory cells deep in the mucosa (interstitial) during maintenance from $38 \%$ to $47 \%$, but this was not significant. There were no significant differences between the three treatment groups with regard to any of these parameters of gastritis during maintenance.

\section{Discussion}

Definition of the best approach to longterm medical management of reflux disease has become particularly important since the finding that suppression of acid secretion with omeprazole for two months is highly effective for healing of oesophagitis and relief of symptoms. ${ }^{10}$ There has been the expectation that healing the oesophagitis would produce a lasting remission by interrupting the vicious cycle of events whereby the oesophagitis further impairs the anti-reflux mechanism. This hope has not been realised, as it is now clear that in most patients with erosive oesophagitis, relapse occurs within days to weeks of stopping acid suppressant treatment. This study is the first randomised, controlled comparison between longterm omeprazole given in two dose regimens, and ranitidine at conventional full dose, after initial healing of oesophagitis with omeprazole. The results show very clearly that omeprazole $20 \mathrm{mg}$ daily is highly effective as a maintenance therapy. In the patient group studied, weekend omeprazole therapy, or ranitidine at the standard ulcer healing dose of $150 \mathrm{mg}$ twice daily were associated with an unacceptably high relapse rate, presumably as a result of inadequate acid suppression.

It is most unlikely that there are any confounding factors that could account for the highly significant difference in relapse rates of patients treated with omeprazole $20 \mathrm{mg}$ daily, when compared with the other two treatment groups. Each group contained a substantial number of patients, and randomisation after healing with omeprazole resulted in good matching for demographic features and the severity of oesophagitis at the time of trial entry (Table I). Our results are consistent with other studies that have evaluated the longterm medical management of reflux disease. In patients with moderate to severe peptic oesophagitis, intractability has been the usual pattern, as evidenced by the poor control achieved with non-drug measures and by the high relapse rate seen after withdrawal of omeprazole after healing of oesophagitis with this agent. " The low success rate with ranitidine seen in this study is also consistent with previous maintenance trials with this agent in reflux disease. At least for patients with erosive or 
ulcerative oesophagitis, the degree of acid suppression produced by ranitidine $150 \mathrm{mg}$ twice daily does not seem to be sufficient for a useful maintenance effect.

The high level of efficacy of omeprazole $20 \mathrm{mg}$ daily found in this study is in accord with the substantial uncontrolled experience of treatment of oesophagitis (given daily in doses of $20 \mathrm{mg}$ to $60 \mathrm{mg}$ ), where $\mathrm{H}_{2}-\mathrm{RA}$ treatment has failed. Our data are also consistent with, but complementary to, the findings of the two other published formal evaluations of maintenance treatment for reflux disease with omeprazole. Lundell et al ${ }^{12}$ selected a group of patients who had not healed after at least three months' treatment with standard doses of $\mathrm{H}_{2}-\mathrm{RA}$ and treated them with either omeprazole $20 \mathrm{mg}$ every morning or ranitidine $300 \mathrm{mg}$ twice daily for four to 12 weeks. Those patients who healed were then given maintenance treatment with the same agent at half the dose. Hence the results are not strictly comparable with ours, as non-randomisation after healing may have introduced a bias towards milder patients in the ranitidine group. Even allowing for such a bias, however, the ranitidine group fared badly, with only $10 \%$ remaining in remission compared with $67 \%$ on omeprazole. Another study completed recently by Laursen et $a l^{13}$ compared randomised maintenance treatment with omeprazole $20 \mathrm{mg}$ every morning, omeprazole $10 \mathrm{mg}$ every morning, or placebo (over six months) in a group of patients who had been healed by omeprazole $20 \mathrm{mg}$ every morning. Both $10 \mathrm{mg}$ and $20 \mathrm{mg}$ were effective in preventing relapse compared with placebo, although the $20 \mathrm{mg}$ dose was more effective, maintaining $58 \%$ of patients in remission compared with $34 \%$ on the lower dose. These remission rates are not strictly comparable with those found in the other studies, however, as relapse also included less specific oesophagitis, for example, diffuse hyperaemia, with or without symptoms. Isal et al $^{14}$ also tested the lower dose of omeprazole (10 mg every morning) compared with weekend dosing with $20 \mathrm{mg}$ every morning and found, contrary with our expectation, that $79 \%$ of patients treated with $10 \mathrm{mg}$ every morning remained in remission at six months. As in our study, however, they found weekend omeprazole to be less effective than daily treatment, as it maintained only $46 \%$ of patients in remission after six months.

Our trial was designed to give reliable and sensitive general monitoring for safety and adverse events. Both of the study drugs were well tolerated, with no clinically significant events or laboratory changes being seen, which could reasonably be attributed to the treatment used. It should be noted though, that because of the high relapse rate in the patients randomised to weekend omeprazole and ranitidine, the amount of information available with omeprazole $20 \mathrm{mg}$ daily was substantially greater.

The serial biopsy specimens of the gastric mucosa were taken to explore the possibility that longterm omeprazole might have effects on gastric mucosal histology. The total number of endocrine cells did not change significantly during the study. This is in keeping with other studies that have shown only a slight increase in the total number of argyrophil cells in body mucosa during up to five years' treatment with omeprazole..$^{1516}$

Similarly, there was no significant increase in the number of patients showing focal hyperplasia (as defined by Solcia et al $1988^{8}$ ) of the argyrophil cells during our study. Over a longer period of follow up (up to four years), Solcia $e t$ al $l^{17}$ found some progression of gastritis in omeprazole treated patients, which generally went hand in hand with increases in focal collections of argyrophil cells. They have suggested that this is a consequence of collapse of the atrophying glands, with loss of other specialised glandular cells but preservation of the endocrine cells. This conclusion is supported by the finding of a similar progression of gastritis and endocrine cell clustering in other patients followed up for several years but not treated with omeprazole or other antisecretory drugs. ${ }^{18}$

The slight but significant worsening of gastritis during the healing phase of the study stabilised thereafter, so that there was no further change during the longer maintenance phase. A similar increase of gastritis severity and activity in the oxyntic (but not antral) mucosa has been seen recently during short term treatment of duodenal ulcer patients with omeprazole, ${ }^{19}$ ranitidine or antacids..$^{20}$ No such effect was seen in patients receiving combined treatment with omeprazole and antibiotics resulting in Helicobacter pylori eradication. ${ }^{19}$ It seems possible that an increase of luminal $\mathrm{pH}$ may render the mucosal barrier more permeable to bacterial toxins and antigens, thus causing a more vigorous inflammatory response to $H$ pylori or to other luminal organisms. The overall conclusion, however, from the histological assessments in this study is that few changes in endocrine cell populations and general histology of the corpus mucosa occurred during a 12 month period of treatment, with any of the antisecretory regimens that we used.

This study adds significantly to important principles now emerging about the treatment of reflux disease. While previous studies have shown that the endoscopic severity of oesophagitis is a good predictor of its healing responsiveness, we have shown that there is a similar relation between the amount of acid suppression and the successful maintenance of healing and symptom control. While the levels of acid suppression produced by omeprazole $20 \mathrm{mg}$ daily were sufficient to maintain virtually all patients, the few patients who remained relapse free on weekend omeprazole or daily ranitidine generally had milder oesophagitis, that is grade 2 (Fig 3). This finding emphasises the importance of grading the oesophagitis in clinical studies, as outcomes will be substantially influenced by the spectrum of severity of the disease in the study population. In the longterm treatment of reflux disease, therefore, the dose of acid suppressant treatment should be adjusted according to endoscopic severity and response. This study establishes that omeprazole is the first highly effective longterm maintenance treatment for prevention of relapse of reflux oesophagitis and that daily dosing is superior dosing with the $20 \mathrm{mg}$ omeprazole regimen. 
Associate investigators for this study: Royal Adelaide Hospital: Drs R J Fitch, R H Holloway, D P Reid, R D Johnson, J T LaBrooy, R J L Fraser, R Britten Jones; Flinders Medical Centre, Adelaide: Drs R L Willing, D R Williams, P J Pritchard; Sir Charles Gairdner Hospital, Perth: Drs S E Edmunds, R Sallie, W C Connell, B R Beveridge, B H Laurence, NE E Hoffman, Prof R Jone; S Sathananthan, H A J Harley.

The Chief Investigators also thank the following clinical trial The Chief Investigators also thank the following clinical trial
nurses, pharmacists and trial coordinators who were essential to nurses, pharmacists and trial coordinators who were essential to
the success of the trial. Sister W Ferguson, Sister J Morcom, Sister J Fennell, Mrs S Keys, Mr D Cosh, Ms Susan Devenish-Meares. J Fennell, Mrs S Keys, Mr D Cosh, Ms Susan Devenish-Meares.
Mr G Tomasich provided essential technical assistance with $\mathrm{Mr} \mathrm{G}$ Tomasich provided essential technical assistance with
evaluation of gastric biopsy specimens and we thank Dr M Frame for assistance with the manuscript.

1 Hetzel DJ, Dent J, Reed WD, Narielvala FM, Mackinnon M, McCarthy $\mathrm{JH}$, et al. Healing and relapse of severe peptic oesophagitis after treatment with omeprazole. Gastroenterology 1988; 95: 903-12.

2 Sandmark S, Carlsson R, Fausa O, Lundell L. Omeprazole or ranitidine in the treatment of reflux oesophagitis. Results of a ranitidine in the treatment of reflux oesophagitis. Results of a double-blind, randomised, Scandinavia 3 Lind T, Cederberg C, Ekenved G, Haglund U, Olbe L. Effect
of omeprazole - a gastric proton pump inhibitor - on pentagastrin stimulated acid secretion in man. Gut 1983; 24: $270-6$.

4 Prichard PJ, Yeomans ND, Mihaly GW. Omeprazole: a study of its inhibition of gastric $\mathrm{pH}$ and oral pharmacokinetics after morning or evening dosage. Gastroenterology 1985; 88: 64-9.

5 Andersson $T$, Andrén $K$, Cederberg $C$, Lagerström $P O$ Lundborg P, Skånberg I. Pharmacokinetics and bioavailability of omeprazole after simple and repeated administration in healthy subjects. $\mathrm{Br} \mathcal{f}$ Clin Pharmacol 1990; 29. $557-63$.

6 Grimelius L. A silver nitrate stain for $\mathrm{A}_{2}$-cells in human pancreatic islets. Acta Societatis Medicorum Upsaliensis pancreatic islets. Acta Socie

7 Misiewicz J, Tytgat G, Goodwin C, Price A, Sipponen P, Strickland $\mathrm{R}$, et al. The Sydney System: a new classification of gastritis. Sydney: WCOG, working party reports 1990 $1-10$

8 Solcia E, Bordi C, Creutzfeldt W, Dayal Y, Dayan AD, Falkner S, et al. Histopathological classification of non- antral gastric endocrine growths in man. Digestion 1988; 41 : $185-200$.

9 Pocock SJ. Clinical trials. A practical approach. Chichester: Wiley, 1983: 221-7.

10 Sontag SJ, Hirschowitz BI, Holt S, Robinson MG, Behar J, Berenson $M M$, et al. Two doses of omeprazole versus placebo in symptomatic erosive oesophagitis: the US multiplacebo in symptomatic erosive oesophagitis: the

11 Bell NJV, Hunt RH. Role of gastric acid suppression in the treatment of gastro-oesophageal reflux disease. Gut 1992; 33 . treatme 118 .

12 Lundell L, Backman L, Ekström P, Enander L-K, Falkmer S, Fausa $\mathrm{O}$, et al. Prevention of relapse of reflux oesophagitis after endoscopic healing: the efficacy and safety of omeprazole compared with ranitidine. Scand F Gastroenterol 1991; 26: 248-56.

13 Laursen LS, Bondesen S, Hansen J, Sanchez G, Sebelin E, Havelund T, et al. Omeprazole $10 \mathrm{mg}$ or $20 \mathrm{mg}$ daily for the prevention of relapse in gastroesophageal reflux disease? A double-blind comparative study. Gastroenterology 1992; 102. A 109 .

14 Isal JP, Zeitoun P, Barbier P, Cayphas JP, Carlsson R. Comparison of two dosage regimens of omeprazole - $10 \mathrm{mg}$
once daily and $20 \mathrm{mg}$ weekends - as prophylaxis against once daily and $20 \mathrm{mg}$ weekends - as prophylaxis against recu

15 Creutzfeldt W, Lamberts R. Inter-relationship between serum gastrin levels, gastric mucosal histology and gastric endocrine cell growth. Digestion 1992; 51 (suppl 1): 76-81.

16 Brunner GHG, Lamberts R, Creutzfeldt W. Efficacy and safety of omeprazole in the long-term treatment of peptic ulcer and reflux oesophagitis resistant to ranitidine. Digestion 1990; 47: 64-8.

17 Solcia E, Fiocca R, Havu N, Dalväg A, Carlsson R. Gastric endocrine cells and gastritis in patients receiving long-term omeprazole treatment. Digestion 1992; 51 (suppl 1): 82-92.

18 Havu N, Maaroos HI, Sipponen P. Argyrophil cell hyperplasia associated with chronic corpus gastritis in gastric ulcer disease. Scand 7 Gastroenterol 1991; 26 (suppl 186): 90-4.

19 Fiocca R, Villiani L, Luinetti O, Gianatti A, Boldorini R Lazzaroni $M$, et al. Helicobacter pylori (HP) eradication and sequential clearance of inflammation in duodenal ulce patients treated with omeprazole and antibiotics. Ir $\mathcal{F ~ M e d}$ Sci 1992; 161 (suppl 10): 93-4.

20 Stolte M, Bethke B, Blum AL, Sulser E, Stadelmann O Antacid treatment has a deleterious effect on the severity and activity of gastritis of the corpus mucosa. Ir f Med Sci 1992 161 (suppl 10): 6. 